\title{
Influence of dose, gender, and cigarette smoking on clozapine plasma concentrations
}

This article was published in the following Dove Press journal:

Neuropsychiatric Disease and Treatment

Michaela Mayerova, ${ }^{1-3}$ Libor Ustohal, ${ }^{1-3}$ Jiri Jarkovsky, ${ }^{4}$ Jan Pivnicka, ${ }^{1,5}$ Tomas Kasparek, ${ }^{1,2}$ Eva Ceskova ${ }^{1,3}$

'Faculty of Medicine, Masaryk University, Brno, Czech Republic; ${ }^{2}$ Department of Psychiatry, University Hospital Brno, Brno, Czech Republic; ${ }^{3}$ CEITEC - Central European Institute of Technology, Masaryk University, Brno, Czech Republic; ${ }^{4}$ Institute of Biostatistics and Analyses, Masaryk University, Brno, Czech Republic; ${ }^{5}$ Institute of Forensic Medicine, St. Anne's University Hospital, Masaryk University, Brno, Czech Republic

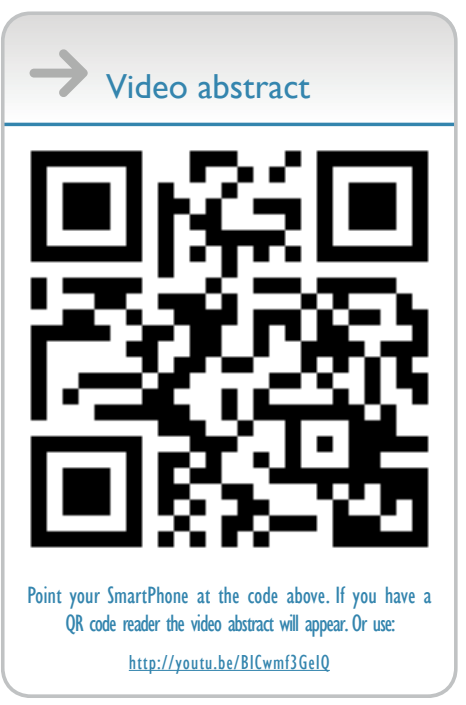

Correspondence: Libor Ustohal Department of Psychiatry, University Hospital Brno, Jihlavska 20, Brno 625 00, Czech Republic

Tel +420532232055

Email ustohal.libor@fnbrno.cz
Introduction: Therapeutic drug monitoring (TDM) of clozapine is a very useful method for verifying both the correct intake and the interindividual variability of its metabolism, thereby avoiding the risk of toxicity. The purposes of this paper were to discover how many patients using clozapine in common clinical practice have clozapine plasma concentration (PC) levels in the proposed reference range and to identify factors that influence clozapine PC levels.

Methods: Our study included 100 inpatients (diagnosed with schizophrenia or schizoaffective disorder) taking standard doses of clozapine (100-700 mg/day). Clozapine concentration was measured by high-performance liquid chromatography. Correlations between doses and PC levels and the influence of smoking and gender on clozapine PC levels were calculated.

Results: A large number of the patients (67\%) had PC levels outside the proposed reference range. The clozapine PC levels were influenced by dose, gender, and cigarette smoking.

Conclusion: The correlations between dose, gender, and cigarette smoking and clozapine PC levels highlighted by our study overlap other research. It was surprising to find such a large number of patients with clozapine PC levels outside the therapeutic range. This result suggests the importance of clozapine TDM due to misunderstood inter- and/or intraindividual variability or misestimated partial therapeutic compliance.

Keywords: therapeutic drug monitoring, plasma levels, interindividual variability, schizophrenia, schizoaffective disorder

\section{Introduction}

In individuals with clearly defined treatment-resistant schizophrenia, clozapine should be introduced as the treatment of choice because of its superior efficacy in this regard. ${ }^{1}$ Clozapine treatment reduces the number of patients hospitalized and the number of bed days. ${ }^{2}$ Although approximately one-third of patients with schizophrenia show treatment resistance, the number of patients treated with clozapine is lower. ${ }^{3}$ However, clozapine prescription is increasing in most investigated countries. In most of the 17 observed countries, clozapine use peaks at age 40-59 years; there is a male preponderance in clozapine use. ${ }^{3}$ The early-onset group (15-20 years of age) of patients with schizophrenia shows the highest cumulative clozapine use rate. ${ }^{4}$ Clozapine can cause a broad spectrum of adverse effects. Most are benign, tolerable, and manageable, ${ }^{5}$ but some can be severe and life-threatening, including myocarditis, ileus, and agranulocytosis. ${ }^{6}$ There is a strong correlation between clozapine plasma concentration (PC) and seizures; most other clozapine side effects seem to be independent from clozapine PC. ${ }^{7,8}$

Clozapine PC levels show large interindividual variability ${ }^{9,10}$ and a considerable percentage of patients have clozapine $\mathrm{PC}$ outside the reference range. ${ }^{11,16,17}$ Clozapine PC can be influenced by many factors: dose, ${ }^{11-13}$ gender,,${ }^{13-16}$ age,${ }^{13,15-17}$ body weight, ${ }^{16}$ smoking,,$^{11,15,16,18-20}$ caffeine, ${ }^{12,21,22}$ and comedication ${ }^{11,12}$ (Table 1). 


\begin{tabular}{|c|c|c|c|c|c|c|c|c|c|c|c|c|}
\hline 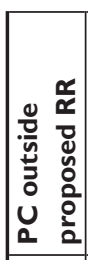 & & $\underline{z}$ & $\Sigma$ & $\underline{z} \bar{z}$ & 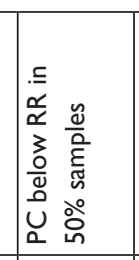 & 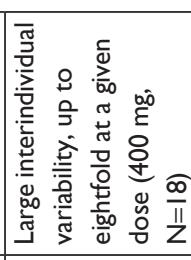 & 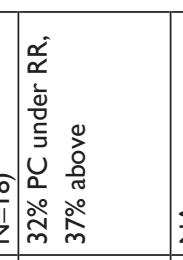 & $\mathbb{z}$ & $\underline{z}$ & $\underline{z}$ & $\mathbb{z}$ & $\underline{z}$ \\
\hline 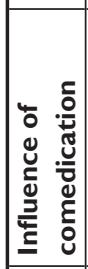 & 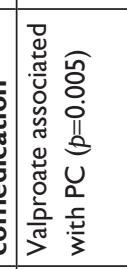 & 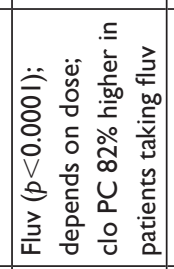 & & $\mathbb{z} \frac{\mathbb{Z}}{z}$ & $\mathbb{z}$ & $\underline{z}$ & $\mathbb{z}$ & $\mathbb{z}$ & $\underline{z}$ & $\underline{z}$ & $\frac{\Sigma}{z}$ & $\underline{z}$ \\
\hline 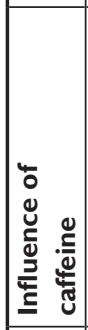 & 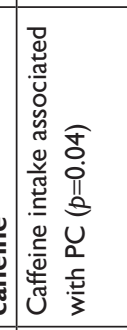 & $\mathbb{z}$ & $\underline{z}$ & $\mathbb{z} \frac{\mathbb{Z}}{z}$ & 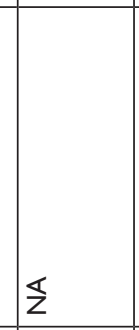 & $\underline{z}$ & $\mathbb{z}$ & $\mathbb{z}$ & $\mathbb{z}$ & ż & 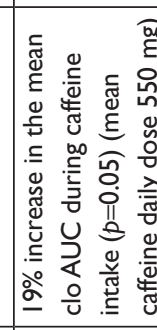 & 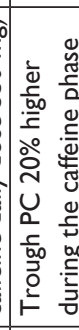 \\
\hline 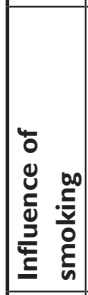 & & 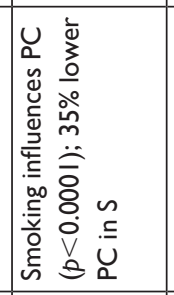 & $\underline{z}$ & 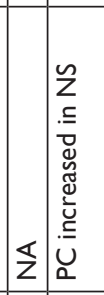 & 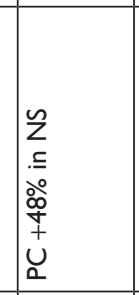 & 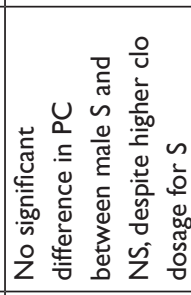 & $\frac{1}{z}$ & 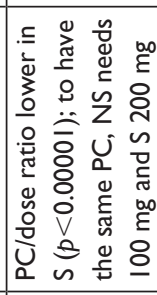 & 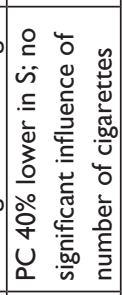 & 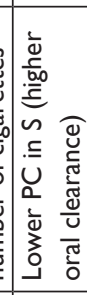 & $\frac{1}{z}$ & $\underline{z}$ \\
\hline 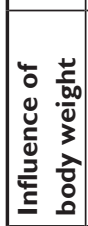 & & $\underline{z}$ & 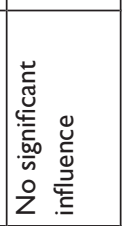 & $\mathbb{z} \frac{\mathbb{z}}{z}$ & 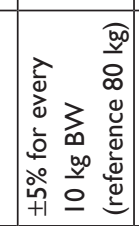 & $\frac{1}{z}$ & $\mathbb{Z}$ & 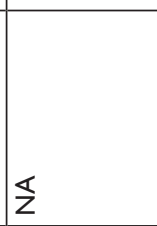 & 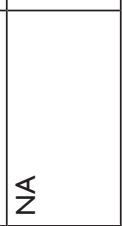 & $\$$ & 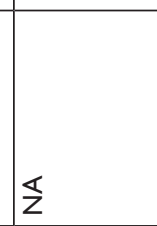 & 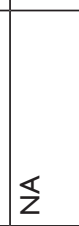 \\
\hline 芯 & & 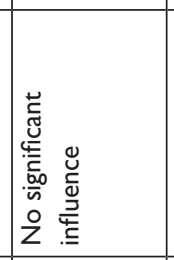 & 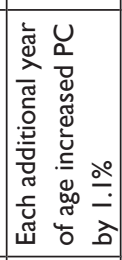 & 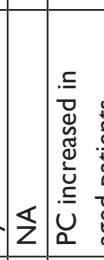 & 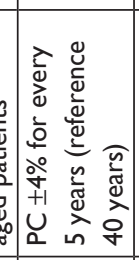 & 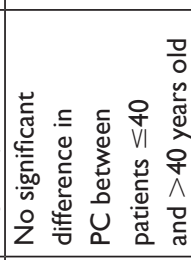 & 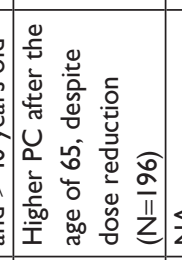 & $\bar{z}$ & $\bar{z}$ & & $\mathbb{z}$ & $\underline{z}$ \\
\hline 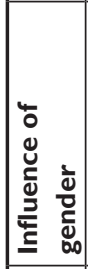 & & 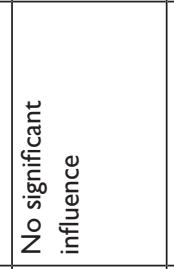 & 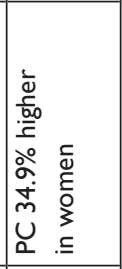 & 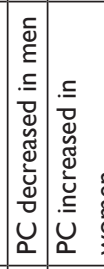 & 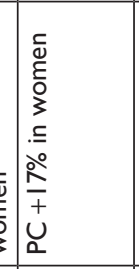 & 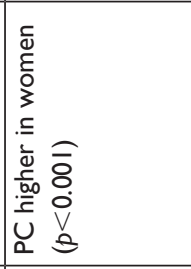 & 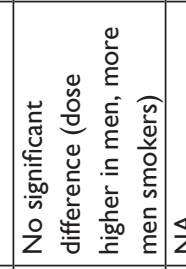 & & 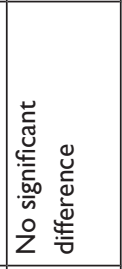 & 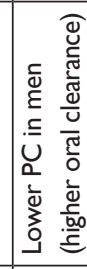 & : & $\bar{z}$ \\
\hline 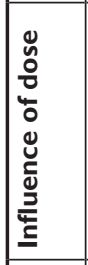 & 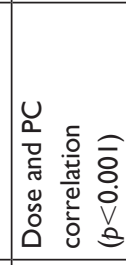 & 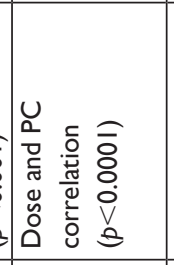 & 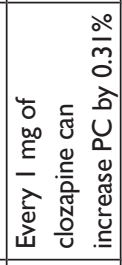 & & $\mathbb{z}$ & $\underline{z}$ & $\mathbb{Z}$ & $\overleftarrow{z}$ & $\underline{z}$ & $\overleftarrow{z}$ & $\underline{z}$ & $\underline{z}$ \\
\hline 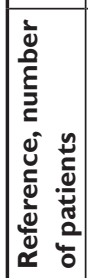 & 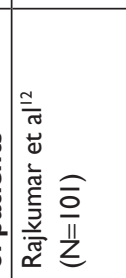 & 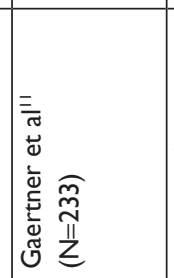 & 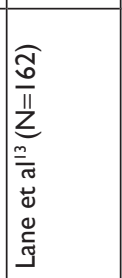 & 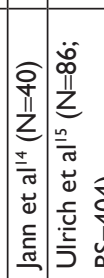 & 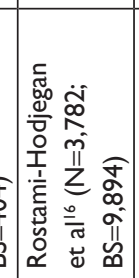 & 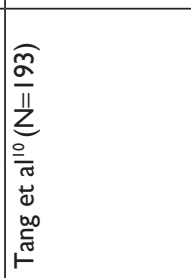 & 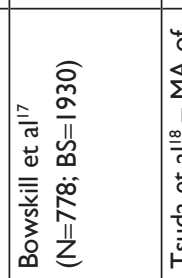 & 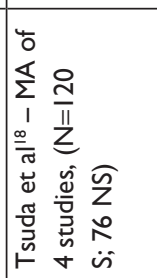 & 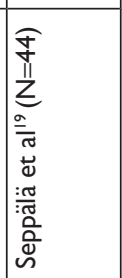 & 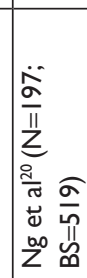 & 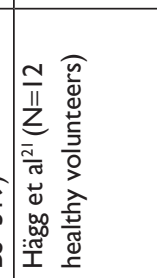 & 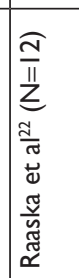 \\
\hline
\end{tabular}


There is a significant difference in clozapine PC between men and women. When administered the same clozapine dose, women have higher PC than men. ${ }^{10,13-16,20}$ The difference between the genders is explained by lower cytochrome P450 1A2 (CYP1A2) activity in women. ${ }^{23}$ Other influential factors include slower gastric emptying in women, more adipose tissue in women, lower glomerular filtration rate, renal tubular secretion, reabsorption in women, ${ }^{24}$ and lower liver blood flow in women. ${ }^{25}$ Other potential factors include the effects of estrogen, as an inhibitor of CYP1A2, ${ }^{25}$ and oral contraceptives. Higher progesterone levels may induce cytochrome P450 3A4 (CYP3A4). ${ }^{9}$ This issue requires more investigation.

The influence of age, which is based on findings that the activity of CYP1A2 decreases with increasing age, ${ }^{21}$ seems to be mild. However, a study by Relling did not confirm these findings. ${ }^{26}$ The results of research investigating the impact of body weight or of BMI on clozapine PC were inconsistent. ${ }^{13,16}$

Clozapine is metabolized by CYP1A2 and CYP3A4 and partially also by cytochrome P450 2C19 (CYP2C19). Inductors of these enzymes decrease and inhibitors increase PC. Polycyclic aromatic hydrocarbons in cigarettes are inductors of CYP1A2. ${ }^{27}$ Therefore, smokers need higher doses of clozapine to reach recommended clozapine PC levels than nonsmokers do. A considerable number of studies have examined the influence of smoking on clozapine PC; the most significant seems to be the meta-analysis by Tsuda et a $1^{18}$ (Table 1). One question is whether the number of cigarettes smoked per day plays a role. The results are inconsistent. According to Haslemo et al, the maximal induction of CYP1A2 is with 7-12 cigarettes a day, and this does not increase with a higher number of cigarettes. However, this small study $(\mathrm{N}=40)$ did not include any smokers who smoked fewer than seven cigarettes a day. ${ }^{28}$ In 118 healthy volunteers in a study by Dobrinas, the number of cigarettes smoked per day influenced CYP1A2 activity. ${ }^{29}$ According to EPA Guidance 2014 (EPA Guidance on tobacco dependence and strategies for smoking cessation in people with mental illness), PC should be measured just after smoking cessation in cases of medication where such measurement is necessary (for instance, on clozapine).$^{30}$ To simplify the issue of the influence of smoking on clozapine PC, a male smoker needs higher doses of clozapine than a female nonsmoker to have the same PC, which is the practical message included in many cited studies.

Caffeine in daily doses of $400-1,000 \mathrm{mg}$ inhibits the metabolism of clozapine to an extent that might be clinically significant in certain individuals. According to Mitchell, there are $75-165 \mathrm{mg}$ of caffeine in an 8 ounce $(237 \mathrm{~mL})$ cup of coffee ${ }^{31}$ The influence of caffeine on clozapine PC seems to be rather mild ${ }^{21,22}$ (Table 1).

In this context, therapeutic drug monitoring (TDM) of clozapine is very useful in practice, because it is of great importance for patients to take an appropriate dose of clozapine. According to the "Consensus Guidelines for Therapeutic Drug Monitoring in Neuropsychopharmacology: Update 2017", TDM of clozapine is highly recommended.?

The purposes of this paper were to discover how many patients using clozapine in common clinical practice have clozapine $\mathrm{PC}$ levels in the proposed reference range and to identify factors that influence clozapine PC levels.

\section{Methods}

\section{Subjects}

The patient population was 100 inpatients diagnosed with schizophrenia or schizoaffective disorder. The diagnoses were made by a treating clinician according to the International Statistical Classification of Diseases and Related Health Problems 10th Revision. These patients were consecutively hospitalized at the Department of Psychiatry at University Hospital Brno from October 2011 to October 2014. Pharmacoresistance was defined as the failure of two therapeutic attempts with antipsychotic medications from two different receptor groups after a sufficient time. The minimal time of treatment with two other antipsychotic medications before clozapine was 2 months in total: two patients had at least 3 weeks with the first antipsychotic and at least 5 weeks with the second antipsychotic; in the other patients, the previous time of treatment was longer.

All patients provided written informed consent and the study was approved by the Ethics Committee of the University Hospital Brno, Czech Republic.

\section{Clinical assessment}

The psychopathologic status of the patients was measured by Clinical Global Impression - Severity Scale (CGI-S). The patients who were switched to clozapine during the hospitalization were measured just before switching. The patients who had been taking clozapine before the hospitalization were measured at the beginning of the hospitalization.

Patient age (years) and duration of education (years) were registered. Relationship status was simplified into two groups: in a relationship (married patients and patients who had a partner) or not in a relationship (single patients and divorced patients). Employment status was also simplified into two groups: employed patients (patients with a job and students) or unemployed (disability pensioned patients and 
patients without a job). Other registered parameters were the duration of illness (months) and duration of clozapine treatment, which was counted from the day of the final, therapeutic dose (months).

During the hospitalization, the patients smoked in the smoking room at the psychiatric department in hospital, where smoking was permitted. The number of smoked cigarettes a day was identified by questioning the patients. No patient ceased smoking during the hospitalization. The height and weight of each patient were measured before taking a blood sample. The patients were allowed to drink no more than one cup of coffee a day. The exact amount of caffeine received per day was not measured.

Only a few patients received comedication that could influence clozapine plasma level. No patient took fluvoxamine, four patients took proton-pump inhibitors, and six patients took valproate.

Genetic tests were not performed, so information about patients' CYP450 gene polymorphism is not known.

\section{Clozapine dosing}

During the hospitalization, clozapine PC was measured. Nurses consistently verified that the pills were swallowed. The clozapine dose was from 100 to $700 \mathrm{mg} /$ day. The daily dosages were divided into two or three doses, except for one patient who took the whole daily dose of $100 \mathrm{mg}$ in the evening. The morning dose was taken at $8 \mathrm{am}$, the afternoon dose at $1 \mathrm{pm}$, and the evening dose at $8 \mathrm{pm}$. In the patients who were switched to clozapine during the current hospitalization, clozapine was slowly titrated, usually starting at 12.5-25 mg clozapine a day and increasing up to $50 \mathrm{mg}$ a day to the target therapeutic dose.

\section{Sampling and drug analysis}

Blood samples were drawn after at least 7 days at the target therapeutic dose to keep four elimination half-times and steady state. Some patients had taken clozapine before hospitalization, but even their blood samples were taken after at least 7 days of taking the therapeutic dose at the department. Peripheral blood samples were taken at $6 \mathrm{am}$, before the morning dose of clozapine, into biochemical test tubes.

The clozapine PC was measured using high-performance liquid chromatography (HPLC) at the Institute of Forensic Medicine, St Anne's University Hospital in Brno. The blood sample $(0.5 \mathrm{~mL})$ was processed by extraction into $5 \mathrm{~mL}$ 1-chlorobutane after $\mathrm{pH}$ adjustment by $200 \mu \mathrm{L}$ of $0.2 \mathrm{M}$ solution of sodium carbonate in water. Next, $4.5 \mathrm{~mL}$ of separated organic layer of 1-chlorobutane was transferred to a second test tube and re-extracted into $200 \mu \mathrm{L}$ of $0.05 \mathrm{M}$ water solution of sulfuric acid. Calibration solutions of standards were processed analogically. The obtained reextract was analyzed using a method of HPLC coupled to photodiode-array detector using the HPLC Gynkotek device. Chromatographic software Chromeleon, v. 6.80, was used for evaluation and verification. Clozapine was detected on the basis of the measurement of the UV/VIS absorption spectra (200-595 nm), and quantification was performed at $220 \mathrm{~nm}$. The method was validated in accordance with the recommended guidelines of the National Authorisation Centre for Clinical Laboratories, J. E. Purkyne Czech Medical Society.

The limit of quantification for clozapine is $0.008 \mathrm{mg} / \mathrm{L}$ (8 ng/mL).

\section{Comparisons and statistics}

Standard descriptive statistics were applied in the analysis; median supplemented by 5 th-95th percentile range for continuous data, absolute and relative frequencies for categorical data. The statistical significance of between-group differences was tested using the Mann-Whitney $U$-test for continuous data and Fisher's exact test for categorical data. Characteristics influencing clozapine PC levels were evaluated using univariate and multivariate linear regression models; logarithmic transformation was applied when necessary. Analysis was computed using SPSS 25.0.0.1 (IBM Corporation, 2017).

\section{Results \\ Patient characteristics}

These results relate to 98 patients (68 men, 30 women). Two completely noncompliant patients were excluded (even from statistics). (To verify their complete noncompliance, the PC levels of these two patients were measured repeatedly and were repeatedly negative.)

All the patients were White Europeans. The average age was $35.67 \pm 11.90$ years. The average body weight was $84.72 \pm 17.42 \mathrm{~kg}$, and the average body mass index was $27.59 \pm 6.06$. Of the 98 patients, 76 had been diagnosed with schizophrenia (62 paranoid, six hebephrenic, three catatonic, four undifferentiated, and one residual), and 22 with schizoaffective disorder (1 manic, 16 depressive, and five mixed types). The duration of illness varied widely, from patients with their first episode (criteria of pharmacoresistance had been met) to patient with 38 years duration (average duration was $149.18 \pm 140.47$ months; median 120). The duration of clozapine treatment also varied, from 7 days at the therapeutic 
dose (not including days of titration) to 17 years and 7 months. Most of the patients were markedly to extremely ill (16 patients were scored CGI-S=7, 36 patients were scored CGI-S=6, and 29 patients were scored CGI-S=5). A smaller number were borderline to moderately ill (10 patients were scored $\mathrm{CGI}-\mathrm{S}=4$, four patients were scored CGI-S=3, and three patients were scored CGI-S=2).

\section{Clozapine doses and clozapine PCs}

On daily clozapine doses of 100-700 mg/day (the average daily dose was $344 \pm 122.5 \mathrm{mg}$ a day) the measured clozapine $\mathrm{PC}$ level ranged from "negative" $(<8 \mathrm{ng} / \mathrm{mL})$ to $1,900 \mathrm{ng} / \mathrm{mL}$, with the average clozapine PC level at $480.6 \pm 335.5 \mathrm{ng} / \mathrm{mL}$.

Figure 1 shows a correlation between daily dose and clozapine PC levels. The clozapine PC levels of $67 \%$ of patients were outside the proposed reference range (proposed reference range $350-600 \mathrm{ng} / \mathrm{mL}$ ); ${ }^{28}$ the levels of $43 \%$ were above and $24 \%$ of patients had levels below the proposed reference range. The highest clozapine PC level was 1,900 ng/mL when taking $600 \mathrm{mg}$ clozapine per day. This patient was hospitalized for anticholinergic delirium caused by clozapine intoxication when he stopped smoking nicotine cigarettes before the hospitalization (the patient had been smoking 60 cigarettes a day, then stopped smoking and did

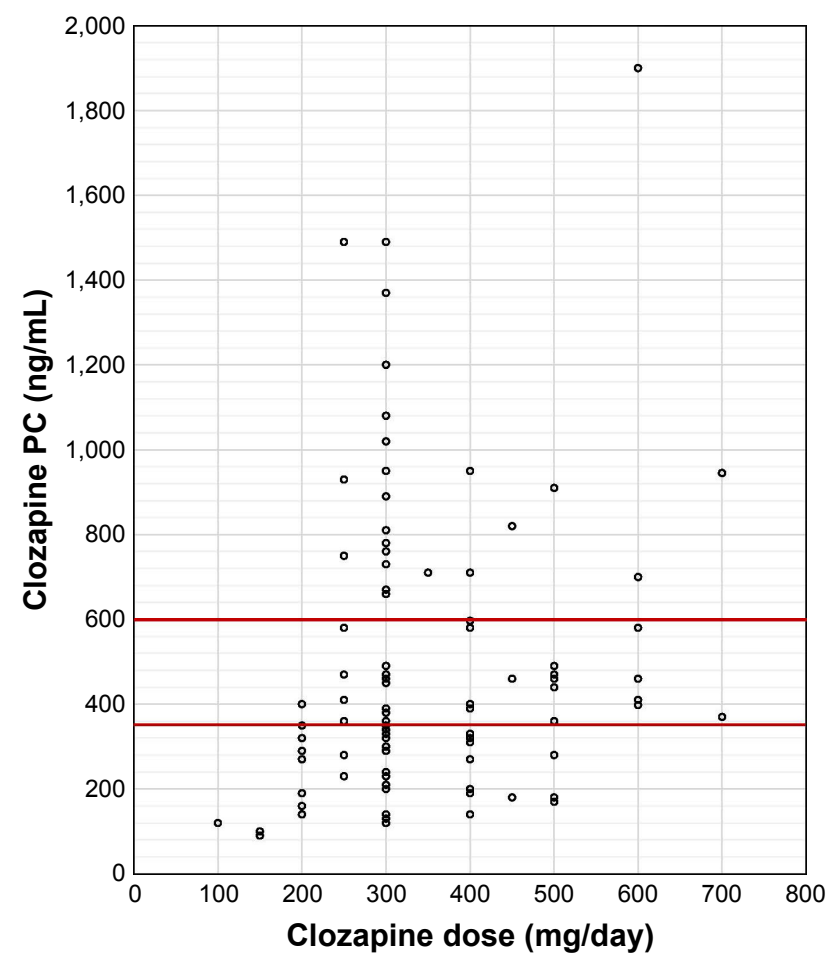

Figure I Correlation of clozapine daily dose and PC.

Notes: Number of patients: 98. Horizontal red lines = reference range.

Abbreviation: PC, plasma concentrations. not inform his doctor). Six other patients with clozapine PC levels above the laboratory alert level $(1,000 \mathrm{ng} / \mathrm{mL})^{28}$ had usual side effects such as hypersalivation, obstipation, and sedation; none of them experienced severe side effects such as epileptic seizures, myocarditis, or neutropenia. Nevertheless, the daily dose of clozapine was reduced.

Only one patient experienced epileptic seizures related to clozapine treatment. One patient had to discontinue clozapine subsequently during the hospitalization because of urinary retention. Both of these patients had clozapine PC levels below the proposed reference range.

There was a significant correlation between the daily dose of clozapine and clozapine PC level $(p<0.001)$.

\section{Influence of smoking on clozapine PC}

There were 46 smokers and 52 nonsmokers. In smokers, the average daily number of cigarettes was 24.2 cigarettes (ranging from three to 45 cigarettes per day). There were more men among the smokers. Smokers were more often in relationships, had higher body weights, and were more often diagnosed with schizoaffective disorder than nonsmokers. Smokers had lower CGI-S than nonsmokers (Table 2).

There was a negative correlation between smoking and clozapine PC level ( $p<0.001$; Table 2).

However, there was no significant correlation between the number of cigarettes per day and clozapine PC level $(p=0.862)$.

\section{Influence of gender on clozapine PC}

There were 68 men and 30 women. There were more smokers among the men than among the women, the men had higher body weights, were taking higher clozapine doses, and had lower CGI-S than the women (Table 3).

There was no statistically significant difference in clozapine PC between genders. But when taking clozapine daily doses and body weights into consideration, there was a statistically significant difference in clozapine PC between men and women, with women having higher clozapine PC $(p=0.021)$.

\section{Influence of other factors}

When using a regression model and identifying predictors associated with clozapine PC, only smoking and clozapine daily dose were statistically significant (in both univariate and multivariate models $)(p<0.001)$. The severity of psychopathology (CGI-S $>5$ ) was statistically significant only in the univariate model; when considering other factors in the multivariate model, there was no statistical significance (Table 4). 
Table 2 Comparison of patient characteristics according to smoking status

\begin{tabular}{|c|c|c|c|}
\hline Characteristics & Nonsmokers $(\mathrm{N}=52)^{\mathrm{a}}$ & Smokers $(\mathbf{N}=46)^{\mathrm{a}}$ & $p$-value ${ }^{b}$ \\
\hline Men & $30(57.7 \%)$ & 38 (82.6\%) & 0.009 \\
\hline Education (years) & $13(9 ; 19)$ & $12(9 ; 16)$ & 0.410 \\
\hline Employment & $9(17.3 \%)$ & $10(21.7 \%)$ & 0.617 \\
\hline Relationship & $4(7.7 \%)$ & $12(26.1 \%)$ & 0.026 \\
\hline Weight (kg) & $78(54 ; 108)$ & $89(63 ; 122)$ & 0.050 \\
\hline BMI & $26(19 ; 36)$ & $27(19 ; 38)$ & 0.133 \\
\hline Diagnosis F25 & $7(13.5 \%)$ & $15(32.6 \%)$ & 0.030 \\
\hline Clozapine dose (mg/day) & $300(200 ; 600)$ & $300(200 ; 600)$ & 0.058 \\
\hline Clozapine PC (ng/mL) & $460(140 ; 1,490)$ & $300(120 ; 730)$ & $<\mathbf{0 . 0 0 1}$ \\
\hline Age (years) & $34(17 ; 55)$ & $35(20 ; 55)$ & 0.743 \\
\hline Length of disease (months) & $102(4 ; 420)$ & $125(3 ; 426)$ & 0.317 \\
\hline Length of disease $>$ I year & $43(82.7 \%)$ & $39(84.8 \%)$ & 1.000 \\
\hline Length of clozapine usage (months) & $0.3(0.3 ; 180.0)$ & $14.0(0.3 ; 72.0)$ & 0.287 \\
\hline Length of clozapine usage $>$ I month & $23(44.2 \%)$ & $28(60.9 \%)$ & 0.110 \\
\hline CGI-S & $6(4 ; 7)$ & $5(3 ; 6)$ & $<0.001$ \\
\hline CGI-S $>4$ & $48(92.3 \%)$ & 33 (7I.7\%) & 0.014 \\
\hline CGI-S $>5$ & 37 (7I.2\%) & 15 (32.6\%) & $<\mathbf{0 . 0 0 1}$ \\
\hline
\end{tabular}

Notes: a Median supplemented by 5 th-95th percentile range for continuous data, absolute and relative frequencies for categorical data. ${ }^{b}$ Mann-Whitney $U$-test for continuous data, Fisher's exact test for categorical data. Significant $p$-values $(p \leq 0.05)$ are shown in bold.

Abbreviations: BMI, body mass index; CGI-S, Clinical Global Impression - Severity Scale; F25, schizoaffective disorder; N, number of patients; PC, plasma concentration.

Body weight, body mass index, age, duration of illness, and duration of clozapine treatment had no statistically significant influence. Neither did the diagnosis schizophrenia versus schizoaffective disorder, relationship status, employment status, or education (Table 4).

\section{Discussion}

This study examined whether patients taking standard doses of clozapine have the clozapine plasma levels in the proposed reference range. The factors influencing clozapine plasma levels were also investigated.

We had expected a high number of the patients to have clozapine PC outside the proposed reference range, but the very high percentage (67\%) was surprising. This percentage was high even though most of the patients were treated with a standard daily dose of clozapine (average dose was $344 \mathrm{mg}$ /day). The number of values outside proposed reference range in our study is similar to the results of a study

Table 3 Comparison of patients' characteristics according to gender

\begin{tabular}{|c|c|c|c|}
\hline Characteristics & Women $(\mathbf{N}=30)^{a}$ & $\operatorname{Men}(\mathbf{N}=68)^{a}$ & $p$-value ${ }^{b}$ \\
\hline Education (years) & $12(9 ; 19)$ & $13(9 ; 18)$ & 0.904 \\
\hline Employment & $5(16.7 \%)$ & $14(20.6 \%)$ & 0.785 \\
\hline Relationship & $6(20.0 \%)$ & $10(14.7 \%)$ & 0.559 \\
\hline Smoking & $8(26.7 \%)$ & $38(55.9 \%)$ & 0.009 \\
\hline Weight (kg) & $76(53 ; 122)$ & $88(63 ; 115)$ & 0.030 \\
\hline BMI & $27(19 ; 43)$ & $27(19 ; 35)$ & 0.734 \\
\hline Diagnosis F25 & $4(13.3 \%)$ & $18(26.5 \%)$ & 0.194 \\
\hline Clozapine dose (mg/day) & $300(150 ; 500)$ & $300(200 ; 600)$ & 0.004 \\
\hline Clozapine PC (ng/mL) & $390(120 ; 1,370)$ & $370(140 ; 950)$ & 0.331 \\
\hline Age (years) & $36(20 ; 56)$ & $33(18 ; 55)$ & 0.159 \\
\hline Length of disease (months) & $142(3 ; 420)$ & $119(4 ; 426)$ & 0.627 \\
\hline Length of disease $>$ I year & $26(86.7 \%)$ & $56(82.4 \%)$ & 0.770 \\
\hline Length of clozapine usage (months) & $0.3(0.3 ; 132.0)$ & $5.0(0.3 ; 154.0)$ & 0.259 \\
\hline Length of clozapine usage $>$ I month & $13(43.3 \%)$ & $38(55.9 \%)$ & 0.279 \\
\hline CGI-S & $6(5 ; 7)$ & $5(3 ; 7)$ & 0.002 \\
\hline CGI-S $>4$ & $30(100.0 \%)$ & $5 \mathrm{I}(75.0 \%)$ & 0.001 \\
\hline CGI-S $>5$ & 23 (76.7\%) & 29 (42.6\%) & 0.002 \\
\hline
\end{tabular}

Notes: a Median supplemented by 5 th- 95 th percentile range for continuous data, absolute and relative frequencies for categorical data. ${ }^{b}$ Mann-Whitney $U$-test for continuous data, Fisher's exact test for categorical data. Significant $p$-values $(p<0.05)$ are shown in bold.

Abbreviations: BMI, body mass index; CGI-S, Clinical Global Impression - Severity Scale; F25, schizoaffective disorder; N, number of patients; PC, plasma concentration. 
Table 4 Predictors associated with clozapine plasma concentration in linear regression model

\begin{tabular}{|c|c|c|c|c|}
\hline \multirow[t]{2}{*}{ Predictor $^{a}$} & \multicolumn{2}{|l|}{ Univariate model } & \multicolumn{2}{|l|}{ Multivariate model } \\
\hline & Beta $(95 \% \mathrm{Cl})$ & p-value & Beta $(95 \% \mathrm{Cl})$ & $p$-value \\
\hline Men & $-0.114(-0.445 ; 0.122)$ & 0.262 & & \\
\hline Education (years) & $0.042(-0.525 ; 0.799)$ & 0.683 & & \\
\hline Employment & $-0.023(-0.37 I ; 0.296)$ & 0.823 & & \\
\hline Relationship & $0.019(-0.323 ; 0.389)$ & 0.854 & & \\
\hline Smoking & $-0.400(-0.764 ;-0.280)$ & $<0.00 \mathrm{I}$ & $-0.432(-0.802 ;-0.323)$ & $<0.001$ \\
\hline Weight (kg) & $0.121(-0.25 \mathrm{I} ; 1.010)$ & 0.235 & & \\
\hline BMI & $0.126(-0.227 ; 0.988)$ & 0.217 & & \\
\hline Diagnosis F25 & $0.034(-0.263 ; 0.369)$ & 0.740 & & \\
\hline Clozapine dose (mg/day) & $0.34 \mathrm{I}(0.270 ; 0.954)$ & $<0.00 \mathrm{I}$ & $0.405(0.423 ; 1.033)$ & $<0.001$ \\
\hline Age (years) & $0.023(-0.010 ; 0.012)$ & 0.819 & & \\
\hline Length of disease (months) & $0.114(-0.052 ; 0.186)$ & 0.264 & & \\
\hline Length of disease $>$ I year & $0.133(-0.119 ; 0.588)$ & 0.191 & & \\
\hline Length of clozapine usage $>$ I month & $-0.092(-0.382 ; 0.143)$ & 0.370 & & \\
\hline CGI-S & $0.195(-0.002 ; 0.218)$ & 0.054 & & \\
\hline CGI-S $>4$ & $0.069(-0.229 ; 0.465)$ & 0.500 & & \\
\hline CGI-S >5 & $0.226(0.038 ; 0.552)$ & 0.025 & $0.071(-0.144 ; 0.330)$ & 0.439 \\
\hline
\end{tabular}

Notes: ${ }^{\mathrm{A} A l l}$ continuous predictors with the exception of age were log transformed prior to regression analysis; the evaluated variable clozapine PC was also log transformed. Significant $p$-values $(p<0.05)$ are shown in bold.

Abbreviations: BMI, body mass index; CGI-S, Clinical Global Impression - Severity Scale; F25, schizoaffective disorder.

by Couchman in which $70.9 \%$ of the values were outside the proposed reference range. In contrast to the study by Couchman, in which more PC levels were below the proposed reference range ( $42.5 \%$ under and $28.4 \%$ above), in our study more PC levels were above (43\% above and $24 \%$ under). Couchman's analysis was conducted on a considerably larger group of patients $(\mathrm{N}=26,796$ patients, and 104,127 blood samples). ${ }^{9}$

Figure 1 shows the broad range of clozapine $\mathrm{PC}$ in our data. For example, if we focus on patients taking $300 \mathrm{mg}$ clozapine a day, the value is reflected in a wide range of $120-1,490 \mathrm{ng} / \mathrm{mL}$, which shows the strong interindividual variability of clozapine PC.

Full noncompliance was discovered in two patients, despite consistent monitoring of medication administration at the department. These two patients had negative clozapine $\mathrm{PC}$, even in repeated measurement. (These patients were subsequently treated by long-lasting antipsychotic injections.)

There was a statistically significant correlation between clozapine daily doses and clozapine PC levels. This result had been expected and correspond with other published studies conducted with similar or larger numbers of patients. ${ }^{11,12}$

There was a negative correlation between smoking and clozapine PC in our study ( $p<0.001)$, which had been expected. It is in accordance with the induction of CYP1A2 by polyaromatic hydrocarbons in cigarettes. An influence of smoking on clozapine PC was observed in the meta-analysis by Tsuda et al. ${ }^{18}$ In our study, there was no significant correlation between the number of cigarettes smoked a day and clozapine PC. That could be explained by the results of the study by Haslemo et al, ${ }^{28}$ in which the maximum induction of CYP1A2 was with 7-12 cigarettes a day, and the induction did not increase with a higher number of cigarettes.

A difference between genders, taking into consideration clozapine daily doses and body weights, in our data is evident. Women had significantly higher clozapine PC than men, which is in accordance with other studies. . $^{10,13-16,20}$

If we consider strong interindividual variability, the influence of smoking, and the risk of potentially dangerous side effects of clozapine, TDM of clozapine can be a very useful method in practice. This is particularly true for patients who are being treated with clozapine for the first time, who do not have sufficient therapeutic efficacy on clozapine, and who experience side effects. Hiemke et al highly recommend TDM of clozapine. ${ }^{7}$ A significant proportion of patients considered to be treatment resistant have subtherapeutic antipsychotic plasma levels, ${ }^{32}$ and this is associated with subsequent admission. ${ }^{33}$

Patients who switched to clozapine are treatment resistant and need to set the therapy as effectively as possible with optimal doses. Clozapine can cause potentially dangerous side effects. Taking one blood sample is usually not a burden for patients, even in the context of regular monitoring of white cells. Nevertheless, some patients can ask for voluntary discontinuation because of discomfort with the mandatory blood monitoring scheme. ${ }^{34}$ If we consider all these facts, there is a 
clear benefit of TDM of clozapine in patients who switched to clozapine. Furthermore, TDM of clozapine seems to be particularly important for patients who start or stop smoking.

If noncompliance is suspected, TDM can be a useful method of detection. Complete noncompliance can be easily discovered; however, it is nearly impossible to discover partial noncompliance.

Our results suggest the importance of clozapine TDM in order to improve the efficacy and the safety of clozapine treatment. Further studies are necessary to investigate the inter/intraindividual variability of clozapine metabolism and to better evaluate the treatment adherence of patients.

The advantages of this study are related to its naturalistic observation: data are from common clinical practice and patients were not selected.

The study has some limitations: the number of smoked cigarettes a day was ascertained according to information from patients and was not verified by staff. The exact amount of caffeine intake per day was not measured. However, no more than one cup of coffee a day is permitted at this department. This amount of received caffeine is probably negligible, because one cup (237 mL) of coffee contains $~ 75-165 \mathrm{mg}$ of caffeine. ${ }^{31}$ Caffeine in daily doses of 400-1,000 $\mathrm{mg}$ increases clozapine PC of $19 \% .{ }^{21}$ Comedication was not taken into consideration, although only a few patients took medication that could influence clozapine metabolism, as reported. Completely but not partially noncompliant patients were discovered. TDM of clozapine was undertaken repeatedly in a minority of patients (for clinical reasons, such as after dose change); the other patients underwent just one blood sample analysis; therefore, it was not possible to establish if they were completely compliant. False-negative and falsepositive results are not probable, but possible.

\section{Acknowledgments}

The authors thank Dr Balazova and Anne Johnson for proofreading the text. Dr Mayerova reports personal fees from the Ministry of Education, Youth and Sports of the Czech Republic, project CEITEC 2020 (LQ1601); grants from the Ministry of Health, Czech Republic, project for conceptual development of research organization 65269705 (University Hospital Brno, Czech Republic); and funds from a research grant from the Grant Agency of the Ministry of Health of the Czech Republic (AZV) 15-31063A, during the conduct of the study. Dr Ustohal reports personal fees from the Ministry of Education, Youth and Sports of the Czech Republic, project CEITEC 2020 (LQ1601) and grants from the Ministry of Health, Czech Republic, project for conceptual development of research organization 65269705 (University Hospital Brno, Czech Republic), during the conduct of the study.

\section{Author contributions}

MM: data sampling, study coordination, literature search, and manuscript editing. LU: data analysis, literature search, and manuscript editing. JJ: statistics gathering. JP: blood sample analysis. TK and EC: supervising and literature search. All authors contributed toward data analysis, drafting and critically revising the paper, gave final approval of the version to be published, and agree to be accountable for all aspects of the work.

\section{Disclosure}

The authors report no conflicts of interest in this work.

\section{References}

1. Hasan A, Falkai P, Wobrock T, et al. World Federation of Societies of Biological Psychiatry (WFSBP) guidelines for biological treatment of Schizophrenia, Part 1: update 2012 on the acute treatment of schizophrenia and the management of treatment resistance. World $J$ Biol Psychiatry. 2012;13(5):318-378.

2. Land R, Siskind D, McArdle P, Kisely S, Winckel K, Hollingworth S. The impact of clozapine on hospital use: a systematic review and meta-analysis. Acta Psychiatr Scand. 2017;135(4):296-309.

3. Bachmann CJ, Aagaard L, Bernardo M, et al. International trends in clozapine use: a study in 17 countries. Acta Psychiatr Scand. 2017;136(1): 37-51.

4. Kim JS, Park CM, Choi J, et al. The association between season of birth, age at onset, and clozapine use in schizophrenia. Acta Psychiatr Scand. 2017;136(5):445-454.

5. Iqbal MM, Swati S, Aneja A, Iqbal MT, Aneja E, Haque S. Most common side effects of clozapine and their management. Int J Emerg Ment Health. 2016;18(4):1-6.

6. Honigfeld G, Arellano F, Sethi J, Bianchini A, Schein J. Reducing clozapine-related morbidity and mortality: 5 years of experience with the Clozaril National Registry. J Clin Psychiatry. 1998;59(Suppl 3): $3-7$.

7. Hiemke C, Bergemann N, Clement HW, et al. Consensus guidelines for therapeutic drug monitoring in neuropsychopharmacology: update 2017. Pharmacopsychiatry. 2018;51(1-2):9-62.

8. Khan A, Preskorn S. Examining concentration-dependent toxicity of clozapine: role of therapeutic drug monitoring. J Psychiatr Pract. 2005;11(5):289-301.

9. Couchman L, Morgan PE, Spencer EP, Flanagan RJ. Plasma clozapine, norclozapine, and the clozapine:norclozapine ratio in relation to prescribed dose and other factors: data from a therapeutic drug monitoring service, 1993-2007. Ther Drug Monit. 2010;32(4):438-447.

10. Tang YL, Mao P, Li FM, et al. Gender, age, smoking behaviour and plasma clozapine concentrations in 193 Chinese inpatients with schizophrenia. Br J Clin Pharmacol. 2007;64(1):49-56.

11. Gaertner I, Gaertner H, Lampe D. Therapeutic drug monitoring of clozapine and olanzapine. Similarities and differences. Psychopharmakotherap. 1999;6(3):105-109.

12. Rajkumar AP, Poonkuzhali B, Kuruvilla A, Jacob M, Jacob KS. Clinical predictors of serum clozapine levels in patients with treatment-resistant schizophrenia. Int Clin Psychopharmacol. 2013;28(1):50-56.

13. Lane HY, Chang YC, Chang WH, Lin SK, Tseng YT, Jann MW. Effects of gender and age on plasma levels of clozapine and its metabolites: analyzed by critical statistics. J Clin Psychiatry. 1999;60(1):36-40. 
14. Jann MW, Liu HC, Wei FC, Lin SK, Hu WH, Chang WH. Gender differences in plasma clozapine levels and its metabolites in schizophrenic patients. Hum Psychopharmacol. 1997;12(5):489-495.

15. Ulrich S, Baumann B, Wolf R, et al. Therapeutic drug monitoring of clozapine and relapse - a retrospective study of routine clinical data. Int J Clin Pharmacol Ther. 2003;41(1):3-13.

16. Rostami-Hodjegan A, Amin AM, Spencer EP, Lennard MS, Tucker GT, Flanagan RJ. Influence of dose, cigarette smoking, age, sex, and metabolic activity on plasma clozapine concentrations: a predictive model and nomograms to aid clozapine dose adjustment and to assess compliance in individual patients. J Clin Psychopharmacol. 2004;24(1): 70-78.

17. Bowskill S, Couchman L, MacCabe JH, Flanagan RJ. Plasma clozapine and norclozapine in relation to prescribed dose and other factors in patients aged 65 years and over: data from a therapeutic drug monitoring service, 1996-2010. Hum Psychopharmacol. 2012;27(3):277-283.

18. Tsuda Y, Saruwatari J, Yasui-Furukori N. Meta-analysis: the effects of smoking on the disposition of two commonly used antipsychotic agents, olanzapine and clozapine. BMJ Open. 2014;4(3):e004216.

19. Seppälä NH, Leinonen EV, Lehtonen ML, Kivistö KT. Clozapine serum concentrations are lower in smoking than in non-smoking schizophrenic patients. Pharmacol Toxicol. 1999;85(5):244-246.

20. $\mathrm{Ng} \mathrm{W}$, Uchida $\mathrm{H}$, Ismail Z, et al. Clozapine exposure and the impact of smoking and gender: a population pharmacokinetic study. Ther Drug Monit. 2009;31(3):360-366.

21. Hägg S, Spigset O, Mjörndal T, Dahlqvist R. Effect of caffeine on clozapine pharmacokinetics in healthy volunteers. Br J Clin Pharmacol. 2000;49(1):59-63.

22. Raaska K, Raitasuo V, Laitila J, Neuvonen PJ.Effect of caffeine-containing versus decaffeinated coffee on serum clozapine concentrations in hospitalised patients. Basic Clin Pharmacol Toxicol. 2004;94(1): 13-18.

23. Pollock BG. Gender differences in psychotropic drug metabolism. Psychopharmacol Bull. 1997;33(2):235-341.
24. Smith S. Gender differences in antipsychotic prescribing. Int Rev Psychiatry. 2010;22(5):472-484.

25. Bigos KL, Pollock BG, Stankevich BA, Bies RR. Sex differences in the pharmacokinetics and pharmacodynamics of antidepressants: an updated review. Gend Med. 2009;6(4):522-543.

26. Relling MV, Lin JS, Ayers GD, Evans WE. Racial and gender differences in $\mathrm{N}$-acetyltransferase, xanthine oxidase, and CYP1A2 activities. Clin Pharmacol Ther. 1992;52(6):643-658.

27. Iqbal J, Sun L, Cao J, et al. Smoke carcinogens cause bone loss through the aryl hydrocarbon receptor and induction of Cyp1 enzymes. Proc Natl Acad Sci U S A. 2013;110(27):11115-11120.

28. Haslemo T, Eikeseth PH, Tanum L, Molden E, Refsum H. The effect of variable cigarette consumption on the interaction with clozapine and olanzapine. Eur J Clin Pharmacol. 2006;62(12):1049-1053.

29. Dobrinas M, Cornuz J, Oneda B, Kohler Serra M, Puhl M, Eap CB. Impact of smoking, smoking cessation, and genetic polymorphisms on CYP1A2 activity and inducibility. Clin Pharmacol Ther. 2011; 90(1):117-125.

30. Rüther T, Bobes J, De Hert M, et al. EPA Guidance on tobacco dependence and strategies for smoking cessation in people with mental illness. Eur Psychiatry. 2014;29(2):65-82.

31. Mitchell DC, Knight CA, Hockenberry J, Teplansky R, Hartman TJ. Beverage caffeine intakes in the US. Food Chem Toxicol. 2014;63: $136-142$.

32. McCutcheon R, Beck K, D’Ambrosio E, et al. Antipsychotic plasma levels in the assessment of poor treatment response in schizophrenia. Acta Psychiatr Scand. 2018;137(1):39-46.

33. Di Lorenzo R, Sagona M, Landi G, Martire L, Piemonte C, Del Giovane C. The revolving door phenomenon in an Italian Acute Psychiatric Ward: a 5-year retrospective Analysis of the potential risk factors. J Nerv Ment Dis. 2016;204(9):686-692.

34. Legge S, Hamshere M, Hayes RD, et al. Reasons for discontinuing clozapine: a cohort study of patients commencing treatment. Schizophr Res. 2016;174(1-3):113-119.
Neuropsychiatric Disease and Treatment

\section{Publish your work in this journal}

Neuropsychiatric Disease and Treatment is an international, peerreviewed journal of clinical therapeutics and pharmacology focusing on concise rapid reporting of clinical or pre-clinical studies on a range of neuropsychiatric and neurological disorders. This journal is indexed on PubMed Central, the 'PsycINFO' database and CAS,

\section{Dovepress}

and is the official journal of The International Neuropsychiatric Association (INA). The manuscript management system is completely online and includes a very quick and fair peer-review system, which is all easy to use. Visit http://www.dovepress.com/testimonials.php to read real quotes from published authors. 